\title{
Geographic origin and timing of colonization of the Pacific Coast of North America by the rocky shore gastropod Littorina sitkana
}

\author{
Peter B Marko ${ }^{\text {Corresp., } 1}$, Nadezhda I Zaslavskaya ${ }^{2}$ \\ ${ }^{1}$ Department of Biology, University of Hawai'i at Mānoa, Honolulu, Hawai'i, United States of America \\ 2 National Scientific Center of Marine Biology, Far Eastern Branch, Russian Academy of Sciences, Vladivostok, Russian Federation \\ Corresponding Author: Peter B Marko \\ Email address: pmarko@hawaii.edu
}

The demographic history of a species can have a lasting impact on its contemporary population genetic structure. Northeastern Pacific (NEP) populations of the rocky shore gastropod Littorina sitkana have very little mitochondrial DNA (mtDNA) sequence diversity and show no significant population structure despite lacking dispersive planktonic larvae. A contrasting pattern of high mtDNA diversity in the northwestern Pacific (NWP) suggests that $L$. sitkana may have recently colonized the NEP from the NWP via stepping-stone colonization through the Aleutian-Commander Archipelago (ACA) following the end of the last glacial 20,000 years ago. Here, we use multi-locus sequence data to test that hypothesis using a combination of descriptive statistics and population divergence modeling aimed at resolving the timing and the geographic origin of NEP populations. Our results show that NEP populations share a common ancestor with a population of $L$. sitkana on the Kamchatka Peninsula $\sim 46,900$ years ago and that NEP populations diverged from each other $\sim 21,400$ years ago. A more recent population divergence between Kamchatka and NEP populations, than between Kamchatka and other populations in the NWP, suggests that the ACA was the most probable dispersal route. Taking into account the confidence intervals for the estimates, we conservatively estimate that $L$. sitkanaarrived in the NEP between 107,400 and 4,100 years ago, a range of dates that is compatible with post-glacial colonization of the NEP. Unlike other congeners that are relatively abundant in the Pleistocene fossil record of the NEP, only one report of $L$. sitkana exists from the NEP fossil record. Although broadly consistent with the molecular data, the biogeographic significance of these fossils is difficult to evaluate, as the shells cannot be distinguished from the closely-related congener $L$. subrotundata. 
1 Geographic origin and timing of colonization of the 2 Pacific Coast of North America by the rocky shore 3 gastropod Littorina sitkana

4

5

\author{
Peter B. Marko ${ }^{1}$ and Nadezhda I. Zaslavskaya ${ }^{2}$ \\ ${ }^{1}$ Department of Biology, University of Hawai' $\mathrm{i}$ at Mānoa, Honolulu, HI, 96822, USA \\ ${ }^{2}$ National Scientific Center of Marine Biology, Far Eastern Branch, Russian Academy of Sciences, \\ Vladivostok, Russia \\ Corresponding Author: \\ Peter B. Marko ${ }^{1}$ \\ ${ }^{1}$ Department of Biology, University of Hawai'i at Mānoa, Honolulu, HI, USA \\ Email address: pmarko@hawaii.edu
}

\begin{abstract}
The demographic history of a species can have a lasting impact on its contemporary population genetic structure. Northeastern Pacific (NEP) populations of the rocky shore gastropod Littorina sitkana have very little mitochondrial DNA (mtDNA) sequence diversity and show no significant population structure despite lacking dispersive planktonic larvae. A contrasting pattern of high mtDNA diversity in the northwestern Pacific (NWP) suggests that L. sitkana may have recently colonized the NEP from the NWP via stepping-stone colonization through the Aleutian-Commander Archipelago (ACA) following the end of the last glacial 20,000 years ago. Here, we use multi-locus sequence data to test that hypothesis using a combination of descriptive statistics and population divergence modeling aimed at resolving the timing and the geographic origin of NEP populations. Our results show that NEP populations share a common ancestor with a population of $L$. sitkana on the Kamchatka Peninsula $\sim 46,900$ years ago and that NEP populations diverged from each other $\sim 21,400$ years ago. A more recent population divergence between Kamchatka and NEP populations, than between Kamchatka and other populations in the NWP, suggests that the ACA was the most probable dispersal route. Taking into account the confidence intervals for the estimates, we conservatively estimate that $L$. sitkana arrived in the NEP between 107,400 and 4,100 years ago, a range of dates that is compatible with post-glacial colonization of the NEP. Unlike other congeners that are relatively abundant in the Pleistocene fossil record of the NEP, only one report of $L$. sitkana exists from the NEP fossil record. Although broadly consistent with the molecular data, the biogeographic significance of these fossils is difficult to evaluate, as the shells cannot be distinguished from the closelyrelated congener L. subrotundata.
\end{abstract}

\title{
Introduction
}

Resolving the contemporary and historical factors affecting patterns of spatial genetic variation is a fundamental goal of population genetics and phylogeography (Slatkin 1985; Avise 2004). For neutral genetic loci, population genetic structure is expected to reflect the combined effects of mutation, genetic drift, and gene flow among populations. Across stable landscapes and seascapes, these evolutionary forces may result in incremental evolutionary divergence among populations, eventually reaching a dynamic evolutionary equilibrium. Large changes to the environment, particularly those that result in 
48

49

50

51

52

53

54

55

56

57

58

59

60

61

62

63

64

65

66

67

68

69

70

71

72

73

74

75

76

77

78

79

80

81

82

83

84

85

86

87

88

89

90

91

92

93

94

95

96

97

major changes in the abundance and distribution of species, may leave long-lasting impacts on spatial patterns of genetic diversity (Whitlock \& McCauley 1999; Neigel 2002). Genetic data are therefore of great use in the field of biogeography, as a tool to understand the evolutionary history of species.

Inferences about the historic biogeography of plants and animals have relied heavily on mitochondrial DNA (mtDNA) sequence data. In addition to being relatively easy to amplify and sequence, the haploid structure and maternal mode of inheritance in most animals results in an effective population size that is one-quarter that of chromosomes in the nuclear genome (Avise et al. 1987). Combined with a relatively high mutation rate, these unusual properties lead to rapid evolutionary divergence between populations, making mtDNA an indispensable and inexpensive tool for detecting population structure, even as genomic data become more common in studies of population genetics and biogeography (Bowen et al. 2014; Hung et al. 2016; Hurst \& Jiggins 2005).

One of the major contributions of mtDNA phylogeography has been frequent characterization of low genetic diversity at high latitudes among plants and animals, a pattern widely interpreted as reflecting post-glacial colonization from low-latitude refugia (e.g., Hewitt et al. 1999; Hewitt 2004; Hoffreiter \& Stewart 2009; Maggs et al. 2008; Marko et al. 2010; Jenkins et al. 2018). Although selective sweeps can create the same pattern (e.g., Wares 2009; Ilves et al. 2010), decreased mtDNA diversity at high latitudes provides a logical and consistent compliment to evidence from the fossil record that shows many large changes in the geographic distributions of species in response to glacial-interglacial climate change during the Pleistocene (Valentine 1989; Valentine and Jablonski 1993; Roy et al. 1996).

In the northeastern Pacific (NEP), mtDNA data from many (but not all) marine species are consistent with the idea that many nearshore benthic species likely retreated to southern refugia during the last glacial maximum (LGM), only recently returning to higher latitudes during the present warm interglacial (e.g., Hellberg 1994; Marko 1998; Edmands 2001; Hickerson \& Cunningham 2005; Marko et al. 2010). Among NEP species with spatial patterns of genetic diversity that are consistent with recent range expansions, several have geographic ranges extending to the northwestern Pacific (NWP) (e.g., Vermeij et al. 1990), leaving open the question that populations in Asia may have served as a glacial refugium for NEP populations of amphi-Pacific taxa (Vermeij 1989). For one such species, the Sitka Periwinkle Littorina sitkana (Philippi 1846), population genetic sub-structuring is nearly non-existent in the NEP (Kyle \& Boulding 2000; Sokolova \& Boulding 2004; Lee \& Boulding 2009; Marko et al. 2010; Botta et al. 2014), but much greater over relatively small spatial scales in the NWP (Nohara 1999; Zaslavskaya \& Pudovkin 2005; Azuma et al. 2017). Based on these contrasting patterns of diversity and the observation that the most common mtDNA haplotype in the NEP is identical to one found in the NWP, Azuma et al. (2017) proposed that NEP populations of L. sitkana must have been derived from the NWP following the end of the last glacial.

Here, we use multi-locus sequence data set to test this hypothesis and to estimate the divergence time of NEP and NWP populations of L. sitkana. Although the smaller effective population size and the greater sensitivity to genetic drift make mtDNA especially useful for detecting range expansions, this aspect of mtDNA evolution, which makes it a "leading indicator" of evolutionary divergence (Zink \& Barrowclough 2008), comes at the cost of rapid loss of polymorphisms within populations and loss of information about demographic parameters such as ancestral population size, gene flow, and divergence times with other populations. Even though the growing use of genomic datasets provides access to thousands of single nucleotide polymorphisms, a handful of additional nuclear sequence loci, from which gene trees can be constructed, may provide sufficiently robust estimates of population genetic parameters that can be used to distinguish between alternative biogeographic histories (Marko \& Hart 2011). To that end, we have combined previously collected sequences with new multi-locus data from populations of $L$. sitkana in the NEP and NWP and have analyzed the data with a combination of descriptive population 
genetic statistics, approximate Bayesian computation modeling of biogeographic histories, and coalescent-based modeling of population divergences.

\section{Materials \& Methods}

\section{Samples and DNA extraction}

Specimens of Littorina sitkana were collected from 14 locations in the summers of 2002 and 2008, seven in the northwestern Pacific (NWP) and seven in the northeastern Pacific (NEP) (Table 1). Collections in Alaska were obtained with permission from the Alaska Department of Fish and Game. In Japan, collections were approved in person at local offices of the Hokkaido Federation of Fisheries Cooperative Associations in Erimo, Nemuro, and Utoro. Collections of marine invertebrates in Russia required no permits. To ensure tissue preservation, each shell was cracked with a small hammer before being placed in ethanol. Genomic DNA was extracted from each individual using a standard CTAB protocol (Marko et al. 2007), re-suspended in water, and stored at $-20^{\circ} \mathrm{C}$.

\section{PCR and sequencing}

Using previously published primers (Folmer et al. 1994; Jarman et al. 2002; Sokolova \& Boulding 2004) and methods (Marko et al. 2010) we amplified and sequenced four loci, including $433 \mathrm{bp}$ of mitochondrial cytochrome $\mathrm{b}($ CYTB $)$ and introns from three nuclear loci: $881 \mathrm{bp}$ of adenosine triphosphate synthase subunit alpha $(A T P S \alpha), 612$ bp of adenosine triphosphate synthase subunit beta $(A T P S \beta)$, and $597 \mathrm{bp}$ of aminopeptidase (APN54). CYTB sequences were collected from new NWP samples (VOS, ERI, NEM, UTO, KHO, STA, PET) but previously published CYTB sequences were electronicallyretrieved for samples from NEP populations (SJI, REN, RUP, CAM, COR, KOD, JUN; GenBank: GQ902686-GQ902751). Mitochondrial DNA (mtDNA) was directly sequenced with both primers, assembled into contigs and edited with Sequencher 4.8 (GeneCodes Corp.), and aligned with other consensus sequences.

For the nuclear DNA (nDNA), we cloned, plated, and sequenced PCR products from a subset of four localities in the west (ERI, KHO, STA, and PET) and three in the east (KOD, COR, JUN) for use in coalescent analyses and demographic modeling. PCR products were inserted into a vector with the pGEM Easy Vector System; Electromax DH10B E. coli cells (Promega) were transformed with the vector by electroporation. Sequences were edited and aligned with Sequencher and then aligned with ClustalX v1.83.1 (Chenna et al. 2003). For each individual, we selected six colonies (clones) from each plate for sequencing; if two clones from the same plate yielded different sequences, we considered that individual to be a heterozygote; individuals were scored as homozygous if all six colonies contained the same sequence. New mtDNA and nDNA data were deposited in GenBank (Accession numbers: MN120839MN120881).

\section{Genetic diversity and population structure}

We used Arlequin version 3.5.1.2 (Excoffier et al. 2005) and DNAsp version 5.10.01 (Rozas et al. 2010) to calculate nucleotide $(\pi)$ and haplotype $(h)$ diversities, Tajima's (1989) $D$, Fu's (1997) $F_{s}$, and RamosOnsins \& Rozas (2002) $R_{2}$. Significance of the descriptive statistics was evaluated with 10,000 permutations (Arlequin) or coalescent simulations (DNAsp) of the data. We then used an analysis of molecular variation (AMOVA) to estimate $\Phi_{S T}$ between all pairs of samples for all four loci. The bestfitting substitution model for each locus was then chosen with ModelTest version 3.8 (Posada \& Crandall 1998; Posada 2006) using the Akaike Information Criterion. The most similar model available in Arlequin was used for the AMOVA. 
148

149

150

151

152

153

154

155

156

157

158

159

160

161

162

163

164

165

166

167

168

169

170

171

172

173

174

175

176

177

178

179

180

181

182

183

184

185

186

187

188

189

190

191

192

193

194

195

196

\section{Haplotype networks}

Because gene trees and coalescent population genetic analyses are usually constructed with the assumption of no intra-locus recombination, we tested the nDNA sequences for evidence of recombination using the pairwise homoplasy index $\left(\Phi_{w}\right)$ statistic (Bruen et al. 2006) in Splitstree 4.10 (Hudson \& Bryant 2006). ATPS $\alpha(\mathrm{P}<0.035)$ and APN54 $(\mathrm{P}<0.01)$ showed significant evidence of recombination whereas $A T P S \beta$ did not $(\mathrm{P}=0.653)$. We then used an implementation of the four-gamete test (Hudson \& Kaplan 1985) in IMgc (Woerner et al. 2007) to exclude putative recombinant nucleotide sites in ATPS $\alpha$ and APN54. After removal of recombinant sites, re-testing with the $\Phi_{w}$ statistic showed no evidence of recombination at either locus $(\mathrm{P}=1.0)$. We then used PopART to construct unrooted minimum spanning networks for each locus (Bandelt et al. 1999).

\section{Pairwise population divergence modeling}

We used IMa2 (Hey \& Nielson 2004) to estimate gene flow, population divergence times, and effective population sizes for all pairwise combinations of samples for which we collected multi-locus data. Pairwise isolation-with-migration (IM) models may be a poor fit to the data (because they ignore migration from other populations), but they have the advantage of greater power given the relatively smaller number of model parameters (compared to multi-population models of divergence). Given that $L$. sitkana does not have planktonic larvae and our samples are separated by hundreds to thousands of $\mathrm{km}$, we used exponential distributions (with a mean of $0.1 / \mu$ ) for the migration priors. Exponential priors are conservative with respect to inferring gene flow (a greatest prior probability at $m=0$ ) but they do not discount the likelihood of gene flow given they lack an explicit upper bound.

IMa2 was run on the University of Hawaii High Performance Computing Cluster in 72 hours intervals (the maximum length of jobs permitted on the cluster) in which the run was repeatedly restarted by loading the state space from the previous run (i.e., as burn-in, without reloading the sampled values from the previous run). After each 72-hour interval, convergence was assessed by comparing the parameter estimates and trend plots between the first and second half of the run. When a run had converged, we then restarted the run as before but with the sampled values from each previous run reloaded until 100,000 genealogies had been sampled. Convergence was also assessed by repeating each pairwise analysis three times with different random number seeds. We converted estimates of genetic diversity $(\Theta)$ and divergence times $(t)$ into demographic quantities (i.e., individuals and years, respectively) using a divergence rate of $1 \%$ per million years. This rate was chosen based on divergence rates inferred for protein-coding mtDNA genes in fossil calibrated phylogenies of gastropods (Marko et al. 2014; O'Dea et al. 2016), including Littorinidae (Reid et al. 1996; Williams et al. 2003; Williams \& Reid 2004; Williams \& Duda 2008).

\section{Multi-population divergence model selection}

For all samples for which we collected multi-locus data, we also used IMa3 (Hey et al. 2018), to infer the best-fitting multi-population tree topology under a full isolation-with-migration (IM) model. The bestfitting tree topology was estimated using migration priors with exponential distributions (with a mean of $0.1 / \mu$ ). The phylogeny selection step was conducted on the computing cluster as described above until the run converged after which the sampled values were reloaded until 100,000 genealogies had been sampled.

ABC modeling of biogeographic scenarios

PeerJ reviewing PDF | (2019:06:38571:1:2:NEW 20 Sep 2019) 
197 Based on the IMa3 results, we compared four biogeographic scenarios with approximate Bayesian

198

199

200

201

202

203

204

205

206

207

208

209

210

211

212

213

214

215

216

217

218

219

220

221

222

223

224

225

226

227

228

229

230

231

232

233

234

235

236

237

238

239

240

241

242

243

244

245

246

computational (ABC) modeling (Fig. 1). The first three scenarios were based on the top (best-fitting) 100 trees from IMa3, each of which contained a monophyletic grouping of NEP populations with PET in the NWP (see Results, below). Scenarios 1 and 2 are consistent with a history in which NEP populations were recently colonized from the NWP (PET) either once (Scenario 1) or twice (Scenario 2). Scenario 3 describes a history in which PET was colonized from a NEP ancestor. Scenario 4 represents the null hypothesis that NEP populations have no close relationship to any NWP population (see Cox et al. 2014). We evaluated scenarios by analyzing simulated data with the same number of individuals, loci, and sequence lengths as in the empirical data.

Given that we could not detect any evidence of gene flow between any populations with either IMa2 or IMa3 (see Results, below), we used DIY ABC 2.0.4 (Cornuet et al. 2010) to model the biogeographic scenarios. We chose large and broadly overlapping uniform priors (Table S1) for demographic parameters (population sizes and divergence times) based on the pairwise upper and lower $95 \%$ highest posterior densities from the IM analyses. The models were evaluated by simulating $1 \times 10^{6}$ data sets for each of the four scenarios followed by a rejection step using all one-sample statistics and three twosample summary statistics (the number of segregating sites, the mean of pairwise differences, and $F_{S T}$ ) available in DIY ABC. The most likely scenario was identified with a polychotomous logistic regression (Cornuet et al. 2008, 2010) computed with 50,000 simulated datasets with summary statistics that were most like those generated from the observed data (Cornuet et al. 2008, 2010).

We assessed confidence in the top two models by estimating the type I and type II error rates from 500 a posteriori simulations of each scenario (Cornuet et al. 2010; Robert et al. 2011). The false-positive rate for a biogeographic scenario is the proportion of times that a scenario was chosen when the data were simulated under an alternative scenario; the false-negative rate is the proportion of times that an alternative scenario was chosen when the data were simulated under the focal scenario.

\section{Multi-population parameter estimates}

We estimated population parameters using both IMa3 and ABC. For IMa3, we first estimated the priors for the demographic parameters using the best-fitting population tree inferred with IMa3 and DIYABC, with hyperpriors for all demographic parameters, such that the parameter priors are included in the state space and updated over the course of the run. The updated parameter priors from this first step are then used in a second IMa3 step in which population divergence times, effective population size, and gene flow are estimated. Convergence was assessed as described above and parameter estimates were obtained after 1,000,000 genealogies had been sampled. Effective population size and population divergence times were estimated with $\mathrm{ABC}$ using a local linear regression on the $1 \%$ closest simulated datasets after use of a logit transformation to parameter values (Beaumont et al. 2008; Cornuet et al. 2008).

\section{Results}

\section{Sequence diversity}

The most common mtDNA haplotype from populations of Littorina sitkana (corresponding to haplotype U9 in Azuma et al. (2017)) dominated NEP samples: 83 of 87 individuals (95\%) in the NEP had this haplotype, with five of seven NEP samples (spanning more than $2300 \mathrm{~km}$ of coastline) fixed for that haplotype (Fig. 2). Only three other haplotypes were found in the NEP, each differing from the most common haplotype at a single nucleotide position. The dominant NEP mtDNA haplotype was also most common in two NWP samples from PET on the Kamchatka Peninsula and STA on the eastern side of Sakhalin Island. Like Azuma et al. (2017) we found that most individuals on the Pacific coast of

Peer) reviewing PDF | (2019:06:38571:1:2:NEW 20 Sep 2019) 
247

248

249

250

251

252

253

254

255

256

257

258

259

260

261

262

263

264

265

266

267

268

269

270

271

272

273

274

275

276

277

278

279

280

281

282

283

284

285

286

287

288

289

290

291

292

293

294

295

296

Hokkaido (ERI \& NEM) had haplotype K2, a majority of individuals from the third Hokkaido sample on the Sea of Okhotsk (UTO) had haplotypes U2 and U16, and haplotypes U36, U16, and V01 were the most abundant in the Sea of Japan (VOS and KHO).

Although haplotype diversity was variable among samples in both regions, on average, western samples had greater mtDNA haplotype and sequence diversity than eastern samples (Table S2). Only two samples had significant values for any tests of neutrality, but none of these statistics can be calculated when haplotype diversity is zero, as was the case for six out of 14 samples, including most ( 5 of 7 ) samples from the NEP (Table S2). All three nDNA genes showed a phylogeographic pattern similar to the mtDNA: NEP samples were dominated by one allele and had lower haplotype and sequence diversity compared to the NWP (Figs. 3-5, Tables S3-5). As with the mtDNA, the dominant nuclear allele in the NEP was also present in the west, and was always found at PET. As with the mtDNA, few neutrality test statistics were significant for the nuclear loci (Tables S3-5).

\section{Spatial patterns of genetic differentiation}

Pairwise estimates of $\Phi_{\mathrm{ST}}$ for L. sitkana show strong and statistically significant mtDNA differentiation between nearly all NWP samples, but no significant differentiation among any NEP samples (Table S6). The majority of pairwise mtDNA $\Phi_{S T}$ estimates between NEP and NWP samples were also large and statistically significant, but some east-west comparisons involving STA and PET yielded relatively low and statistically insignificant values $\left(\Phi_{S T} \leq 0.110\right)$. All three nuclear loci showed spatial patterns of differentiation that were like those from the mtDNA, with relatively low and non-significant estimates of $\Phi_{S T}$ in the NEP, higher and more statistically significant estimates in the NWP, and similarly high but variable values between NEP and NWP samples, some of which were not statistically significant (Tables S7-S9).

\section{Pairwise population divergence models}

All posterior distributions for the pairwise estimates of the population migration rates $(2 \mathrm{Nm})$ between NEP and NWP populations rose asymptotically as $2 \mathrm{Nm}$ approached zero (not shown), meaning that none were significantly different from zero (Table 2). Many estimates of effective population size in the NEP were relatively small, more than an order of magnitude smaller than estimates for NWP populations (Table 2). Population divergence times (Fig. 6) within the NEP were also uniformly small $(\leq 3,038$ years), all with posteriors that overlapped with zero and with a maximum $95 \%$ highest posterior density (HPD) of $\sim 74,200$. In contrast, population divergence times within the NWP were much larger, ranging from $\sim 107,400$ to $\sim 179,900$ years, all with posteriors that did not overlap with zero and all with lowest 95\% HPDs $>19,000$ years. Divergence times between NEP and NWP populations were more variable, but several were smaller than most divergence times within the NWP (Fig. 6, Table 2). In one east-west comparison (PET-JUN), the posterior distribution for the population separation time overlapped with zero.

\section{Multi-population divergence models}

In total, 14,219 different tree topologies were sampled by IMa3. Although four trees had the largest product of posterior clade probability (PPCP), no single tree had relatively high support. However, the top 100 trees sorted by PPCP all included a monophyletic grouping of the three NEP populations (COR, JUN, \& KOD) and the NWP population from the Kamchatka Peninsula (PET). Among these top 100 trees (Table S10), 62 included a monophyletic clade of NEP populations (Trees 1-19, 38-41, 62-100); the remaining 38 (Trees 20-37, 42-61) placed PET as the sister-population to JUN.

Peer) reviewing PDF | (2019:06:38571:1:2:NEW 20 Sep 2019) 


\section{ABC modeling of biogeographic scenarios}

Scenario 1 received significantly greater support (posterior probability $=0.821,95 \%$ credible interval: $0.785-0.857$ ) over Scenario 3 (posterior probability $=0.099,95 \%$ credible interval: $0.075-0.123$ ), the next best-fitting population history (Fig. 7). A posteriori simulations of Scenario 1 showed that the type I error rate was only $15.3 \%$. Based on simulations of the other three scenarios, the average type II error rate was $16.9 \%$.

\section{Multi-population parameter estimates}

Based on the outcome of the topology selection steps, we used Tree 1 (Scenario 1) to estimate demographic parameters with IMa3 and DIYABC. Going backwards in time, IMa3 inferred that NEP populations coalesced down into a common ancestor $\sim 21,400$ years ago $\left(t_{1}, \mathbf{F i g}, \mathbf{8}\right)$, merging with PET in the NWP $\sim 46,900$ years ago $\left(t_{2}, \mathbf{F i g} .8\right)$; the latter population fusion coincided with a quadrupling in effective population size (Table 3). The posterior probabilities for all 42 population migration rate $(2 \mathrm{Nm})$ parameters either overlapped with zero or rose asymptotically as $2 \mathrm{Nm}$ approached zero (not shown), indicating that no gene flow could be detected. The parameter estimates from DIYABC were similar, indicating that the NEP populations coalesced down to a common ancestor $\sim 22,400$ years ago and merged with PET $\sim 54,400$ years ago (Table 4).

\section{Discussion}

Our study provides strong support for Azuma et al.'s (2017) hypothesis that Littorina sitkana recently colonized the northeastern Pacific (NEP) from the northwestern Pacific (NWP). The primary evidence for this conclusion is the extremely recent divergence times among all populations within the NEP and between all NEP populations and some populations in the NWP on Sakhalin Island and the Kamchatka Peninsula. This recent biogeographic connection is evident in the haplotype network of each locus, as the most common allele in the NEP is always the most abundant allele at three of four loci in our new sample from Kamchatka, the northeastern most sampled population in the NWP. Much smaller effective population sizes in the NEP is also consistent with the recent colonization hypothesis, as is the large reduction in population size in the ancestral NEP population (i.e., $q 9 \rightarrow q 8$, Fig. 8).

Consistent with previous studies of L. sitkana (Kyle \& Boulding 2000; Lee \& Boulding 2009; Marko et al., 2010; Azuma et al. 2017), we found very little genetic diversity and no significant population subdivision at all four loci in the NEP, an unexpected pattern for a species that lacks planktonic larvae, but one that is readily explained by a recent range expansion. The consistency of the pattern across loci allows us to rule out the possibility of a mtDNA selective sweep in the NEP, or other hypotheses about natural selection acting directly or indirectly on the genetic markers themselves. Instead of a colonization event, a severe bottleneck on NEP population size during the LGM might cause the loss of most haplotypes (but retention of the most common haplotype) across many loci, creating a pattern similar to a founder effect. However, the most important piece of evidence in this study, evident in both the IMa3 and DIYABC analyses, is that the Kamchatka population (PET) shares a more recent common ancestry with NEP populations than the Kamchatka population does with any other NWP population, a result that can only be explained by the hypothesis that L. sitkana recently dispersed to North America from the NWP.

Lacking a planktonic life history stage, colonization of the NEP was presumably accomplished by rafting of adults or egg masses on floating biological debris (Knox 1960; Johannesson 1988; O'Foighil et al. 1999; Collin 2001; Colson \& Hughes 2004; Waters \& Roy 2004; Thiel and Haye 2006; Gordillo \& Nielsen 2013; Cumming et al. 2014). Although both the ABC and full-likelihood methods yielded similar 
347 results, the arrival of L. sitkana in North America is probably best estimated by the full-likelihood

348

349

350

351

352

353

354

355

356

357

358

359

360

361

362

363

364

365

366

367

368

369

370

371

372

373

374

375

376

377

378

379

380

381

382

383

384

385

386

387

388

389

390

391

392

393

394

395

396

397

methods (Hickerson et al. 2006). The multi-population IMa3 method conservatively bounded this event between 107,400 and 4,100 years ago, the upper bound on the separation of NEP populations from PET $\left(t_{2}, \mathbf{F i g . ~ 8 b}\right)$ and the lower bound on the time at which NEP populations coalesced down into a common ancestor, respectively ( $t_{1}$, Fig. 8b, also see Table 3). The four most recent pairwise IMa2 population estimates of divergence times between NWP and NEP populations (Table 2) all broadly overlapped with this window.

The conventional biogeographic wisdom used to explain how species move between the NEP and NWP is that warm interglacial climates permit stepping-stone colonization across the Aleutian-Commander Archipelago (ACA), whereas cold glacial climates result in extinction of northern populations and the closure of this dispersal corridor (Vermeij 1989; Cox et al. 2014; Azuma et al. 2017). Although the confidence interval on the dispersal window inferred from the multi-population method extends back through nearly all of the last glacial period (to 107,400 years ago), the idea that $L$. sitkana colonized the NEP as the climate warmed since the LGM seems likely given the peak in the highest posterior densities for both the divergence time between NEP populations and PET $\left(t_{2}\right.$, Fig. 8b) and the divergence time among NEP populations $\left(t_{l}, \mathbf{F i g} . \mathbf{8 b}\right)$ are both closer to the end of the LGM than the peak of the last interglacial 125,000 years ago; the arrival time of $L$. sitkana in the NEP is also probably closer to the separation times among NEP populations rather than the separation time between the ancestral population that split away from PET in the NWP. Slightly older than expected divergence times from the molecular data might be a consequence of the potential time-dependency of molecular rates (Ho et al. 2011). Because the substitution rate that we used was based on fossil calibrations, it could be an underestimate of the instantaneous mutation rate (Ho et al., 2007; but see Woodhams, 2006; Emerson, 2007; Navascues \& Emerson, 2009), a more appropriate rate for intraspecific phylogeography (Crandall et al. 2012). Using a faster rate in our analyses, however, would only strengthen the idea that $L$. sitkana recently colonized the NEP. That said, a gross mismatch between the substitution rate and the instantaneous mutation rate seems unlikely given that the point estimates for divergence times within the NEP are $<3,100$ years and the $95 \%$ HPDs overlap with zero. This cross-validation suggests that our fossil-based rates and divergence times estimates are not heavily biased by time-dependency.

Dispersal across the ACA is probably frequent given the large number of rocky shore species whose ranges span the entire archipelago (Vermeij et al. 1990), although this inference assumes that most species were driven out of the ACA during cold glacial climates. Among molluscs whose range endpoints are found within the ACA, most are NEP species, outnumbering NWP species by more than four to one, suggesting that species may have been more likely to travel from east to west than west to east, presumably in the predominantly westward flow of the Alaska Current (Vermeij et al. 1990). Alternatively, the range endpoint data might indicate that biogeographic barriers in the ACA are stronger for NEP species. Despite the large number of taxa distributed across the entire archipelago, L. sitkana is the only species studied with genetic data that shows a phylogeographic history consistent with postglacial dispersal in either direction between the NWP and NEP. Several other species with amphi-Pacific distributions show large differences in genetic diversity between NWP and NEP populations, but all show relatively high levels of genetic differentiation between NWP and NEP populations (Sato et al. 2004; Cassone \& Boulding 2006; Liu et al. 2007; Canino et al. 2010), including reciprocal monophyly of mtDNA lineages (e.g., Cox et al. 2014) that indicates an extended period of isolation with no gene flow. Strong east-west differentiation in these taxa suggests that some of the single nominal species with ranges that span the ACA may be recently-diverged sister species that have come into secondary contact in the ACA, rather than "eastern" or "western" species that have recently dispersed from one end of the ACA to the other.

The relatively sparse fossil record provides little complementary information about changes in rocky shore species distributions, yielding a few snapshots of communities captured in uplifted sedimentary

Peer) reviewing PDF | (2019:06:38571:1:2:NEW 20 Sep 2019) 
398

399

400

401

402

403

404

405

406

407

408

409

410

411

412

413

414

415

416

417

418

419

420

421

422

423

424

425

426

427

428

429

430

431

432

433

434

435

436

437

438

439

440

441

442

443

444

445

446

rocks formed during past sea level high-stands (e.g., Valentine \& Jablonski 1993). However, each of the congeners L. scutulata, L. plena, and L. keenae all are relatively abundant in the NEP Pleistocene fossil record (e.g., Lindberg \& Lipps 1996) and all have much greater mtDNA diversity in the NEP than $L$. sitkana (Kyle \& Boulding 2000, 2009; Lee \& Boulding 2007, 2009; Marko et al. 2010), together indicating that these three species have been relatively abundant in the NEP throughout the Pleistocene. In contrast, only a single record of a junior synonym of $L$. sitkana (L. sitkana var. atkana Dall, 1886) has been reported from the NEP Pleistocene fossil record (Zullo 1969), from a marine terrace in southern Oregon dated at 80,000 years old (+/- 5000 years), deposited during the last glacial, but during a brief period in which summer insolation briefly rose in the northern hemisphere (Muhs et al. 2006). Although falling within the broad window (107,000 - 4,140 years ago) inferred for the arrival of $L$. sitkana in North America, the age of the fossils falls outside the upper bound on the separation times among populations further north in Alaska ( $\sim 67,300$ years, Table 3), populations that should be older if $L$. sitkana dispersed across the ACA, arriving first in Alaska.

However, we and two other taxonomic authorities (DG Reid \& AV Chernyshov) inspected photographs of the fossils (UCMP B-7493) and were unable to provide a positive identification, as the relatively small and smooth shells could be either L. sitkana or L. subrotundata (for a morphological comparison see Reid 1996). Compared to $L$. sitkana, NEP populations of L. subrotundata have four times as many mtDNA haplotypes and greater genetic differentiation among populations in British Columbia (Kyle \& Boulding 2000), suggesting an older history in the NEP and that the 80,000-year-old fossils are L. subrotundata. If the fossils are actually L. sitkana, a first occurrence 80,000 years ago at a relatively low latitude is possible if $L$. sitkana first arrived in the NEP by dispersing directly across the Pacific in the North Pacific Current, a plausible dispersal route highlighted by the recent transport of NWP taxa to the NEP on tsunami debris (Carlton et al. 2017). The genealogical connection between Kamchatka and NEP populations of $L$. sitkana discovered here is not consistent with this idea, unless colonists from Kamchatka were carried south in the Oyashio Current, later merging with the Kuroshio Current, and eventually moving eastward in the North Pacific Current. Genetic analysis of samples from the Aleutian Islands can resolve this question, as stepping-stone colonization across the ACA is expected to create a cline in allele frequencies and gradual decline in genetic diversity (Slatkin \& Excoffier 2012) from west to east.

\section{Conclusions}

In summary, analysis of multi-locus sequence data indicates that extremely low genetic diversity among NEP populations of $L$. sitkana is best explained by a recent and rapid range expansion from the NWP. Although the founder events associated with the spread of $L$. sitkana throughout the NEP depleted mtDNA and nuclear DNA diversity, the four loci that we used contained enough information to estimate the arrival of L. sitkana in North America between 107,400 and 4,100 years ago. Reductions in genetic diversity may ultimately limit range expansions (e.g., Travis et al. 2007; Frankham et al. 2010; Hallatschek \& Nelson 2010; Polechová 2018), but the loss of diversity in NEP populations of L. sitkana did not appear to hamper its expansion throughout the Pacific coast of North America. Further southward expansion may be limited instead by other factors, such as habitat availability, predation, and desiccation of egg masses (Beherens Yamada 1977a,b; 1992). Competition could also play a role, as the habitat of $L$. sitkana shifts from predominantly wave exposed shores in the NWP (Golikov \& Kusakin 1962, 1978; Golikov \& Scarlato 1967) to primarily sheltered shores in the NEP, particularly in British Columbia, Washington, and Oregon (Harger 1972; Behrens 1972; Boulding \& van Alstyne 1993) where L. sitkana appears to be replaced by L. subrotundata on exposed shores (Boulding 1990; Boulding \& van Alstyne 1993). Similar range-wide analyses of genetic diversity in other amphi-Pacific taxa, particularly $L$. subrotundata, will be informative, as they can provide insight into the proportion of NEP and NWP that

Peer] reviewing PDF | (2019:06:38571:1:2:NEW 20 Sep 2019) 
447

448

449

450

451

452

453

454

455

456

457

458

459

460

461

462

463

464

465

466

467

468

469

470

471

472

473

474

475

476

477

478

479

480

481

482

483

484

485

486

487

488

489

490

491

492

493

494

495

are recent colonists and how depletion of genetic diversity during post-glacial colonization events may impact future adaptation and range shifts in response to climate change.

\section{Acknowledgements}

We thank M. Yanagida and K. Vicknair for logistical support and V. Brykov for additional financial support in Russia. V. Duriev provided transportation on Sakhalin Island.

\section{References}

Addicott WO. 1964. A late Pleistocene invertebrate fauna from southwestern Oregon. Journal of Paleontology 38:650-661.

Avise JC. 2004. Molecular markers, natural history, and evolution, 2nd edition. Sinauer, Sunderland.

Avise JC, Arnold J, Ball RM, Bermingham E, Lamb T, Neigel JE, Reeb CA, Saunders NC. 1987. Intraspecific phylogeography: the mitochondrial DNA bridge between population genetics and systematics. Annual Review of Ecology and Systematics 18:489-522.

Azuma N, Zaslavskaya NI, Yamazaki T, Nobetsu T, Chiba S. 2017. Phylogeography of Littorina sitkana in the northwestern Pacific Ocean: evidence of eastward trans-Pacific colonization after the Last Glacial Maximum. Genetica 145:139-149.

Bandelt H, Forster P, Röhl A. 1999. Median-joining networks for inferring intraspecific phylogenies. Molecular Biology and Evolution 16(1):37-48.

Behrens S. 1972. The role of wave impact and desiccation on the distribution of Littorina sitkana Philippi, 1845. Veliger 15:129-132.

Botta AM, Rochette R, Saunders GW, Addison JA, Barbeau MA. 2014. Evidence for genotypic differentiation between marine snails (Littorina sitkana) from the upper- and lower-intertidal zone in Bamfield Inlet (British Columbia, Canada). Journal of Experimental Marine Biology and Ecology 461:389-396.

Boulding EG. 1990. Are the opposing selection pressures on exposed and protected shores sufficient to maintain genetic differentiation between gastropod populations with high intermigration rates? Hydrobiologia 193:41-52.

Boulding EG, Alstyne KL van. 1993. Mechanisms of differential survival and growth of two species of of Littorina on wave-exposed and on protected shores. Journal of Experimental Marine Biology and Ecology 169:139-166.

Bowen BW, Shanker K, Yasuda N, Malay MCD, von der Heyden S, Paulay G, Rocha LA, Selkoe KA, Barber PH, Williams ST, Lessios HA, Crandall ED, Bernardi G, Meyer CP, Carpenter KE, Toonen RJ. 2014. Phylogeography unplugged: comparative geographic surveys in the genomic era. Bulletin of Marine Science 90:13-46.

Bruen TC, Philippe H, Bryant D. 2006. A simple and robust statistical test for detecting the presence of recombination. Genetics 172: 2665-2681.

Canino MF, Spies IB, Cunningham KM, Hauser L, Grant WS. 2010. Multiple ice-age refugia in Pacific cod, Gadus macrocephalus. Molecular Ecology 19:4339-4351.

Carlton JT, Chapman JW, Geller JA, Carlton DA, McCuller MI, Treneman NC, Steves BP, Ruiz, GM. 2017. Tsunami-driven rafting: Transoceanic species dispersal and implications for marine biogeography. Science 357:1402-1406.

Cassone BJ, Boulding EG. 2006. Genetic structure and phylogeography of lined shore crab, Pachygrapsus crassipes, along the northeastern and western Pacific coasts. Marine Biology 149:213226.

Collin R. 2001. The effects of mode of development on phylogeography and population structure of North Atlantic Crepidula (Gastropoda: Calyptraeidae). Molecular Ecology 10:2249-2262. 
496

497

498

499

500

501

502

503

504

505

506

507

508

509

510

511

512

513

514

515

516

517

518

519

520

521

522

523

524

525

526

527

528

529

530

531

532

533

534

535

536

537

538

539

540

541

542

543

544

545

546

Colson I, Hughes RN. 2004. Rapid recovery of genetic diversity of dogwhelk (Nucella lapillus L.) populations after local extinction and recolonization contradicts predictions from life-history characteristics. Molecular Ecology 13:2223-2233.

Cornuet J-M, Santos F, Beaumont MA, Robert CP, Marin J-M, Balding DJ, Guillemaud T, Estoup A. 2008. Inferring population history with DIY ABC: a user-friendly approach to approximate Bayesian computation. Bioinformatics 24:2713-2719.

Cornuet JM, Ravigne V, Estoup A. 2010. Inference on population history and model checking using DNA sequence and microsatellite data with the software DIYABC (v1.0). BMC Bioinformatics 11:401.

Cox LN, Zaslavskaya NI, Marko PB. 2014. Phylogeography and trans-Pacific divergence of the rocky shore gastropod Nucella lima. Journal of Biogeography 41:615-627.

Crandall ED, Sbrocco EJ, DeBoer TS, Barber PH, Carpenter KE. 2012. Expansion dating: calibrating molecular clocks in marine species from expansions onto the Sunda Shelf following the last glacial maximum. Molecular Biology and Evolution 29:707-719.

Cumming RA, Nikula R, Spencer HG, Waters JM. 2014. Transoceanic genetic similarities of kelpassociated sea slug populations: long-distance dispersal via rafting? Journal of Biogeography 41:2357-2370.

Edmands S. 2001. Phylogeography of the intertidal copepod Tigriopus californicus reveals substantially reduced population differentiation at northern latitudes. Molecular Ecology 10:1743-1750.

Emerson BC. 2007. Alarm bells for the molecular clock? No support for Ho et al.'s model of timedependent molecular rate estimates. Systematic Biology 56:337-345.

Excoffier LG, Laval G, Schneider S. 2005. Arlequin ver. 3.0: An integrated software package for population genetics data analysis. Evolutionary Bioinformatics Online 1:47-50.

Folmer O, Black M, Hoeh W, Lutz R, Vrijenhork R. 1994. DNA primers for amplification of mitochondrial cytochrome c oxidase subunit I from diverse metazoan invertebrates. Molecular Marine Biology and Biotechnology 3:294-299.

Frankham R. 2010. Challenges and opportunities of genetic approaches to biological conservation. Biological Conservation 143:1919-1927.

Fu Y-X. 1997. Statistical tests of neutrality of mutations against population growth, hitchhiking and background selection. Genetics 147:915-925.

Gilbert KJ, Sharp NP, Angert AL, Conte GL, Draghi JA, Guillaume F, Hargreaves AL, MattheyDoret R, Whitlock MC, Gilbert K. 2017. Local adaptation interacts with expansion load during range expansion: maladaptation reduces expansion load. The American Naturalist 189:368-380.

Golikov AN, Kusakin OG. 1962. Fauna and ecology of Gastropoda, Prosobranchia from the intertidal zone of the Kurile Islands. Isseldovaniya Dal'nevostochnykh Morei S.S.S.R. 8:248-376.

Golikov AN, Scarlato OA. 1967. Molluscs of Pos'et Bay (Sea of Japan) and their ecology. Trudy Zoologicheskogo Instituta 42:1-154.

Gordillo S, Nielsen SN. 2013. The Australasian muricid gastropod Lepsiellaas Pleistocene visitor to southernmost South America. Acta Palaeontologica Polonica 58:777-783.

Hallatschek O, Nelson DR. 2010. Life at the front of an expanding population. Evolution 64:193-206.

Harger JRE. 1972. Competitive coexistence among intertidal invertebrates. American Scientist 60:600607.

Hellberg ME. 1994. Relationships between inferred levels of gene flow and geographic distance in a philopatric coral, Balanophyllia elegans. Evolution 48:1829-1854.

Hewitt GM. 1999. Post-glacial re-colonization of European biota. Biological Journal of the Linnean Society 68:87-112.

Hewitt GM. 2004. Genetic consequences of climatic oscillations in the Quaternary. Philo- sophical Transactions of the Royal Society B 359:183-195.

Hey J, Nielsen R. 2004. Multilocus methods for estimating population sizes, migration rates and divergence time, with applications to the divergence of Drosophila pseudoobscura and D. persimilis. Genetics 167:747-760.

Peer) reviewing PDF | (2019:06:38571:1:2:NEW 20 Sep 2019) 
547

548

549

550

551

552

553

554

555

556

557

558

559

560

561

562

563

564

565

566

567

568

569

570

571

572

573

574

575

576

577

578

579

580

581

582

583

584

585

586

587

588

589

590

591

592

593

594

595

596

Hey J, Chung Y, Sethuraman A, Lachance J, Tishkoff S, Sousa VC, Wang Y. 2018. Phylogeny estimation by integration over isolation with migration models. Molecular Biology and Evolution 35:2805-2818.

Hickerson MJ, Cunningham CW. 2005. Contrasting Quaternary histories in an ecologically divergent sister pair of low- dispersing intertidal fish (Xiphister) revealed by multilocus DNA analysis. Evolution 59:344-360.

Hickerson MJ, Dolman G, Moritz C. 2006. Comparative phylogeographic summary statistics for testing simultaneous vicariance. Molecular Ecology 15:209-223.

Ho SYW, Heupink TH, Rambaut A, Shapiro B. 2007. Bayesian estimation of sequence damage in ancient DNA. Molecular Biology and Evolution 24:1416-1422.

Ho SYW, Lanfear R, Bromham L, Phillips MJ, Soubrier J, Rodrigo AG, Cooper A. 2011. Timedependent rates of molecular evolution. Molecular Ecology 20:3087-3101

Hofreiter M, Stewart J. 2009. Ecological change, range fluctuations and population dynamics during the Pleistocene. Current Biology 19:R584-R594.

Hudson RR, Kaplan NL. 1985. Statistical properties of the number of recombination events in the history of a sample of DNA sequences. Genetics 111:147-164.

Hudson DH, Bryant D. 2006. Application of phylogenetic networks in evolutionary studies. Molecular Biology and Evolution 23:254-267.

Hung C-M, Drovetski SV, Zink RM. 2016. Matching loci to surveyer to questions asked in Phylogeography. Proceedings of the Royal Society B 283:20152340.

Ilves K, Huang W, Wares JP, Hickerson MJ. 2010. Congruent histories of colonization and/or mitochondrial selective sweeps across the North Atlantic intertidal assemblage. Molecular Ecology 19:4505-4519.

Jenkins TL, Castilho R, Stevens JR. 2018. Meta-analysis of northeast Atlantic marine taxa shows contrasting phylogeographic patterns following post-LGM expansions. PeerJ 6:e5684

Liu J, Gao T, Wu S, Zhang, Y. 2007. Pleistocene isolation in the Northwestern Pacific marginal seas and limited dispersal in a marine fish, Chelon haematocheilus (Temminck \& Schlegel, 1845). Molecular Ecology 16:275-288.

Jarman SN, Ward RD, Elliott NG. 2002. Oligonucleotide primers for PCR amplification of coelomate introns. Marine Biotechnology 4:347-355.

Johannesson K. 1988. The paradox of Rockall: why is a brooding gastropod (Littorina saxatilis) more widespread than one which has a planktonic dispersal stage (L. littorea)? Marine Biology 99:507513.

Kennedy GL. 1978. Pleistocene paleoecology, zoogeography and geochronology of marine invertebrate faunas of the Pacific Northwest Coast (San Francisco Bay to Puget Sound). Unpublished Ph.D. Dissertation, University of California-Davis.

Kennedy GL, Armentrout JM. 1989. A new species of chimney-building Penitella from the Gulf of Alaska (Bivalvia: Pholadidae). Veliger 32:320-325.

Knox GA. 1960. Littoral ecology and biogeography of the Southern Oceans. Proceedings of the Royal Society of London Series B 152:577-624.

Kyle CJ, Boulding EG. 2000. Comparative population genetic structure of marine gastropods (Littorina spp.) with and without pelagic larval dispersal. Marine Biology 137:835-845.

Lee HJ, Boulding EG. 2009. Spatial and temporal population genetic structure of four northeastern Pacific littorinid gastropods: the effect of mode of larval development on variation at one mitochondrial and two nuclear DNA markers. Molecular Ecology 18:2165- 2184.

Librado P, Rozas J. 2009. DnaSP v5: A software for comprehensive analysis of DNA polymorphisms data. Bioinformatics 25:1451-1452.

Lindberg DR, Lipps JH. 1996. Reading the chronicle of quaternary temperate rocky shore faunas. In: Jablonski D, Erwin DH, Lipps JH, eds. Evolutionary Paleobiology. University of Chicago Press, Chicago, 161-182.

Peer) reviewing PDF | (2019:06:38571:1:2:NEW 20 Sep 2019) 
597

598

599

600

601

602

603

604

605

606

607

608

609

610

611

612

613

614

615

616

617

618

619

620

621

622

623

624

625

626

627

628

629

630

631

632

633

634

635

636

637

638

639

640

641

642

643

644

645

646

Maggs C, Castilho R, Foltz D, Henzler C, Jolly M, Kelly J, Olsen J, Perez K, Stam W, Vainola R, Viard F, Wares J. 2008. Evaluating signatures of glacial refugia for North Atlantic benthic marine taxa. Ecology 89:108-122.

Marko PB. 1998. Historical allopatry and the biogeography of speciation in the prosobranch snail genus Nucella. Evolution 52:757-774.

Marko PB, Rogers-Bennett L, Dennis AB. 2007. MtDNA population structure and gene flow in lingcod (Ophiodon elongatus): limited connectivity despite long-lived pelagic larvae. Marine Biology 150:1301-1311.

Marko PB, Hoffman JM, Emme SA, McGovern TM, Keever CC, Cox LN. 2010. The 'ExpansionContraction' model of Pleistocene biogeography: rocky shores suffer a sea change? Molecular Ecology 19:146-169.

Marko PB, Hart MW. 2011. The complex analytical landscape of gene flow inference. Trends in Ecology and Evolution 26:448-456.

Marko PB, Moran AL, Zaslavskaya NI. 2014. Phylogenetics of the gastropod genus Nucella (Neogastropoda, Muricidae): Species identities, timing of diversification, and correlated patterns of life-history evolution. Journal of Molluscan Studies 80: 341-353.

Muhs DR, Simmons KR, Kennedy GL, Ludwig KR, Groves LT. 2006. A cool eastern Pacific Ocean at the close of the Last Interglacial complex. Quaternary Science Reviews 25:235-262.

Navascues M, Emerson BC. 2009. Elevated substitution rate estimates from ancient DNA: model violation and bias of Bayesian methods. Molecular Ecology 18:4390-4397.

Neigel JE. 2002. Is $\mathrm{F}_{\mathrm{ST}}$ obsolete? Conservation Genetics 3:167-173.

Nohara M. 1999. Genetic and conchological variation in Littorina sitkana Philippi (Mollusca, Gastropoda) on Northern Japanese Coasts. Zoological Science 16:309-317.

O'Dea A, Lessios HA, Coates AG, Eytan RI, Restrepo-Moreno SA, Cione AL, Collins LS, de Queiroz A, Farris DW, Norris RD, Stallard RF, Woodburne MO, Aguilera O, Aubry M-P, Berggren WA, Budd AF, Cozzuol MA, Coppard SE, Duque-Caro H, Finnegan S, Gasparini GM, Grossman EL, Johnson KG, Keigwin LD, Knowlton N, Leigh EG, Leonard-Pingel JS, Marko PB, Pyenson ND, Rachello-Dolmen PG, Soibelzon E, Soibelzon L, Todd JA, Vermeij GJ, Jackson JBC. 2016. Formation of the Isthmus of Panama. Science Advances 2:e1600883.

O’Foighil D, Marshall BA, Hilbish TJ, Pino MA. 1999. Trans-Pacific range extension by rafting is inferred for the flat oyster Ostrea chilensis. Biological Bulletin 196:122-126.

Peischl S, Excoffier L. 2015. Expansion load: recessive mutations and the role of standing genetic variation. Molecular Ecology 24:2084-2094.

Petit JR, Jouzel J, Raynaud D, Barkov NI, Barnola JM, Basile I, Bender M, Chappellaz J, Davis J, Delaygue G, Delmotte M, Kotlyakov VM, Legrand M. Lipenkov V, Lorius C, Pépin L, Ritz C, Saltzman E, Stievenard M. 1999. Climate and atmospheric history of the past 420,000 years from the Vostok Ice Core, Antarctica. Nature 399:429-436.

Polechová J. 2018. Is the sky the limit? On the expansion threshold of a species' range. PLoS Biology 16:e2005372.

Posada, D. 2006. ModelTest Server: a web-based tool for the statistical selection of models of nucleotide substitution online. Nucleic Acids Research 34:W700-W703.

Posada D, Crandall KA. 1998. Modeltest: testing the model of DNA substitution. Bioinformatics 14:817-818.

Ramos-Onsins SE, Rozas J. 2002. Statistical properties of new neutrality tests against population growth. Molecular Biology and Evolution 19:2092-100.

Reid DG. 1996. Systematics and evolution of Littorina. The Ray Society, Andover.

Reid DG, Rumbak E, Thomas RH. 1996. DNA, morphology, and fossils: phylogeny and evolutionary rates of the gastropod genus Littorina. Philosophical Transactions: Biological Sciences 351:877-895.

Robert CP, Cornuet JM, Marin JM, Pillai NS. 2011. Lack of confidence in approximate Bayesian computation model choice. Proceedings of the National Academy of Sciences USA 108:15112-15117.

Peer] reviewing PDF | (2019:06:38571:1:2:NEW 20 Sep 2019) 
647

648

649

650

651

652

653

654

655

656

657

658

659

660

661

662

663

664

665

666

667

668

669

670

671

672

673

674

675

676

677

678

679

680

681

682

683

684

685

686

687

688

689

690

691

692

693

694

695

696

Roy K, Valentine JW, Jablonski D, Kidwell SM. 1996. Scales of climatic variability and time averaging in Pleistocene biotas: implications for ecology and evolution. Trends in Ecology and Evolution 11:458-463.

Rozas J, Sánchez-DelBarrio JC, Messeguer X, Rozas R. 2003. DnaSP, DNA polymorphism analyses by the coalescent and other methods. Bioinformatics 19:2496-2497.

Sato S, Kojima H, Ando J, Ando H, Wilmot RL, Seeb LW, Efremov V, LeClair L, Bucholz W, Jin D-K, Urawa S, Kaeriyama M, Urano A, Abe S. 2004. Genetic population structure of chum salmon in the Pacific Rim inferred from mitochondrial DNA sequence variation. Environmental Biology of Fishes 69:37-50.

Slatkin M. 1985. Gene flow in natural populations. Annual Review of Ecology and Systematics 16:393430.

Slatkin M, Excoffier L. 2012. Serial founder effects during range expansion: a apatial analog of genetic drift. Genetics 191:171-181.

Sokolova IM, Boulding EG. 2004. Length polymorphisms in an intron of Aminopeptidase N provide a useful nuclear DNA marker for Littorina species (Caenogastropoda). Journal of Molluscan Studies 70:165-172

Tajima F. 1989. Statistical method for testing the neutral mutation hypothesis by DNA polymorphism. Genetics 125:585-593.

Thiel M, Haye H. 2006. The ecology of rafting in the marine environment. III. Biogeographical and evolutionary consequences. Oceanography and Marine Biology 44:323-429.

Travis JMJ, Munkemuller T, Burton OJ, Best A, Dytham C, Johst K. 2007. Deleterious mutations can surf to high densities on the wave front of an expanding population. Molecular Biology and Evolution 24:2334-2343.

Valentine JW. 1989. How good was the fossil record? Clues from the Californian Pleistocene. Paleobiology 15:83-94.

Valentine JW, Jablonski D. 1993. Fossil communities: compositional variation at many time scales. In: Rickleffs RE, Schluter D, eds. Species diversity in ecological communities: historical and geographic perspectives. University of Chicago Press, Chicago, 341-349.

Vermeij GJ. 1989. Geographical restriction as a guide to the causes of extinction: the case of the cold northern oceans during the Neogene. Paleobiology 15:335-356.

Vermeij GJ, Palmer AR, Lindberg DR. 1990. Range limits and dispersal of molluscs in the Aleutian Islands, Alaska. The Veliger 33:346-354.

Wares JP. 2009. Natural distributions of mitochondrial sequence diversity support new null hypotheses. Evolution 64:1136-1142.

Waters JM, Roy MS. 2004. Out of Africa: the slow train to Australasia. Systematic Biology 53:18-24.

Whitlock MC, McCauley DE. 1999. Short review: indirect measures of gene flow- $\mathrm{F}_{\mathrm{ST}}$ does not equal $1 /(4 \mathrm{Nm}+1)$. Heredity $82: 117-125$.

Williams ST, Reid DG, Littlewood DTJ. 2003. A molecular phylogeny of the Littorininae (Gastropoda: Littorinidae): unequal evolutionary rates, morphological parallelism and biogeography of the Southern Ocean. Molecular Phylogenetics and Evolution 28:60-86.

Williams ST, Reid DG. 2004. Speciation and diversity on tropical rocky shores: global phylogeny of snails of the genus Echinolittorina. Evolution 58:2227-2251.

Williams ST, Duda TF. 2008. Did tectonic activity stimulate Oligo-Miocene speciation in the Indo-West Pacific? Evolution 62:1618-1634.

Woerner AE, Cox MP, Hammer MF. 2007. Recombination-filtered genomic datasets by information maximization. Bioinformatics 23:1851-1853.

Woodhams M. 2006. Can deleterious mutations explain the time dependency of molecular rate estimates? Molecular Biology and Evolution 23:2271-2273.

Zaslavskaya NI, Pudovkin AI. 2005. Macrogeographic genetic variability in the gastropod mollusk Littorina sitkana from Northwest Pacific. Russian Journal of Genetics 41:291-300.

Peer] reviewing PDF | (2019:06:38571:1:2:NEW 20 Sep 2019) 
697 Zink RM, Barrowclough GF. 2008. Mitochondrial DNA under siege in avian Phylogeography.

$698 \quad$ Molecular Ecology 17:2107-2121.

699 Zullo VA. 1969. A late Pleistocene marine invertebrate fauna from Bandon, Oregon. Proceedings of the 700 California Academy of Science 36:347-361.

701 


\section{Table $\mathbf{1}$ (on next page)}

Sample sites.

Localities and sample sizes for phylogeographic analysis of Littorina sitkana. 
1 Table 1 Sample sites. Localities and sample sizes for phylogeographic analysis of Littorina

2 sitkana.

3

4

Locality

N Latitude

Longitude Date

5 Vostok Bay (VOS)

$17 \quad 42.87 \mathrm{~N}$

132.74 E June, 2008

6 Erimo-misaki (ERI)

$1141.93 \mathrm{~N}$

143.23 E June, 2008

7 Nemuro-misaki (NEM)

$14 \quad 43.38 \mathrm{~N}$

145.78 E June, 2008

8 Utoro-misaki (UTO)

$9 \quad 44.06 \mathrm{~N}$

$144.98 \mathrm{E}$

June, 2008

9 Kholmsk (KHO)

$16 \quad 47.05 \mathrm{~N}$

142.05 E July, 2008

10 Starodubskoye (STA)

$8 \quad 47.40 \mathrm{~N}$

142.81 E June, 2008

11 Petropavlovsk-Kamchatsky (PET)

$\begin{array}{ll}16 & 52.91 \mathrm{~N}\end{array}$

158.75 E July, 2008

12 Kodiak Island (KOD)

$9 \quad 57.83 \mathrm{~N}$

$152.41 \mathrm{~W}$

May, 2008

13 Cordova (COR)

$12 \quad 60.59 \mathrm{~N}$

$145.75 \mathrm{~W}$

May, 2002

14 Juneau (JUN)

$8 \quad 58.30 \mathrm{~N}$

$134.43 \mathrm{~W}$

May, 2002

15 Prince Rupert (RUP)

$14 \quad 54.31 \mathrm{~N}$

$130.31 \mathrm{~W}$

May, 2002

16 Campbell River (CAM)

$1150.02 \mathrm{~N}$

$125.18 \mathrm{~W}$

May, 2002

17 Port Renfrew (REN)

$6 \quad 48.55 \mathrm{~N}$

124.44 W May, 2002

18 San Juan Island (SJI)

$6 \quad 48.55 \mathrm{~N}$

$123.01 \mathrm{~W}$

May, 2002 


\section{Table 2 (on next page)}

Pairwise population divergence modeling.

Pairwise IMa2 population estimates of current $\left(\mathrm{N}_{1}\right.$ and $\left.\mathrm{N}_{2}\right)$ and ancestral $\left(\mathrm{N}_{A}\right)$ effective population size, population migration rates $\left(2 \mathrm{~N}_{1} \mathrm{~m}_{1>2}\right.$ and $\left.2 \mathrm{~N}_{2} \mathrm{~m}_{2>1}\right)$ moving forward in time, and divergence time in years (T, with highest posterior density or HPD) for all multilocus samples. NWP: Northwest Pacific; NEP: Northeast Pacific. 
1 Table 2 Pairwise population divergence modeling. Pairwise IMa2 population estimates of current $\left(N_{l}\right.$ and $\left.N_{2}\right)$ and ancestral $\left(N_{A}\right)$ effective population size, population migration rates $\left(2 N_{l} m_{l>2}\right.$ and $\left.2 N_{2} m_{2>1}\right)$ moving forward in time, and divergence time in years ( $T$, with highest posterior density or HPD) for all multilocus samples. NWP: Northwest Pacific; NEP: Northeast Pacific.

\begin{tabular}{|c|c|c|c|c|c|c|c|}
\hline Comparison & $N_{1}$ & $N_{2}$ & $N_{A}$ & $2 N_{l} m_{1>2}$ & $2 \mathrm{~N}_{2} \mathrm{~m}_{2>1}$ & $T$ & 95\% HPD \\
\hline \multicolumn{8}{|l|}{ NWP vs NEP } \\
\hline PET-KOD & 164,538 & 8,829 & 121,197 & 0 & 0 & 35,316 & $1,926-221,953$ \\
\hline STA-KOD & 49,348 & 1,013 & 7,091 & 0 & 0 & 18,909 & $1,466-61,668$ \\
\hline KHO-KOD & 150,851 & 8,510 & 155,492 & 0 & 0 & 96,957 & $11,965-425,374$ \\
\hline ERI-KOD & 297,311 & 8,426 & 164,905 & 0 & 0 & 70,215 & $6,179-373,544$ \\
\hline PET-COR & 156,922 & 88,992 & 190,852 & 0 & 0 & 73,786 & $3,629-240,710$ \\
\hline STA-COR & 162,007 & 33,365 & 45,059 & 0 & 0 & 77,965 & $21,463-176,660$ \\
\hline KHO-COR & 209,098 & 73,960 & 265,709 & 0 & 0 & 189,436 & $47,237-466,041$ \\
\hline ERI-COR & 327,359 & 72,359 & 305,290 & 0 & 0 & 123,015 & $28,036-470,891$ \\
\hline PET-JUN & 137,896 & 16,546 & 118,984 & 0 & 0 & 31,309 & $0-155,058$ \\
\hline STA-JUN & 49,676 & 1,916 & 3,685 & 0 & 0 & 28,578 & $2,820-60,466$ \\
\hline KHO-JUN & 154,453 & 16,836 & 132,493 & 0 & 0 & 122,196 & $24,595-447,010$ \\
\hline ERI-JUN & 310,940 & 19,363 & 110,480 & 0 & 0 & 87,701 & $30,297-512,917$ \\
\hline
\end{tabular}

NEP vs NEP

KOD-COR

$7,287 \quad 39,690$

59,276

0

0

1,565

$0-69,402$

KOD-JUN

2,030

9,699

$1,386 \quad 0$

$0 \quad 646$

$0-22,631$

COR-JUN

24,929

15,018

57,067

0

3,038

$0-74,219$

NWP vs NWP

$\begin{array}{llllllll}\text { ERI-PET } & 302,549 & 101,329 & 168,881 & 0 & 0 & 96,969 & 19,547-336,133 \\ \text { ERI-STA } & 214,996 & 201,823 & 51,279 & 0 & 0 & 179,900 & 79,537-327,935 \\ \text { ERI-KHO } & 235,872 & 135,648 & 171,936 & 0 & 0 & 146,073 & 42,854-488,908 \\ \text { KHO-PET } & 153,504 & 110,548 & 139,607 & 0 & 0 & 149,924 & 43,461-485,485 \\ \text { KHO-STA } & 108,564 & 241,188 & 60,444 & 0 & 0 & 107,351 & 38,496-220,649\end{array}$




\begin{tabular}{llllllll} 
PET-STA & 84,666 & 145,322 & 62,762 & 0 & 0 & 110,305 & $29,879-302,608$ \\
\hline
\end{tabular}

6 


\section{Table 3 (on next page)}

Demographic parameter estimates from the multi-population analysis with IMa3.

Most probable estimate (MPE) and 95\% confidence intervals for effective population size $\left(q_{0-12}\right.$, individuals) and divergence time $\left(t_{0-5}\right.$, years $)$. The posterior probabilities for all 42 different population migration rate $(2 \mathrm{Nm})$ parameters either rose asymptotically as $2 \mathrm{Nm}$ approached zero or broadly overlapped with and are therefore not shown. 
Table 3 Demographic parameter estimates from the multi-population analysis with IMa3. Most probable estimate (MPE) and $95 \%$ confidence intervals for effective population size $\left(\mathrm{q}_{0-12}\right.$, individuals) and divergence time $\left(t_{0-5}\right.$, years). The posterior probabilities for all 42 different population migration rate $(2 \mathrm{Nm})$ parameters either rose asymptotically as $2 \mathrm{Nm}$ approached zero or broadly overlapped with and are therefore not shown.

\begin{tabular}{llll} 
Parameter & Description & MPE & 95\% CI \\
\hline$q_{0}$ & Population size: KOD & 8,448 & $0-820,361$ \\
$q_{1}$ & Population size: COR & 280,391 & $98,063-985,063$ \\
$q_{2}$ & Population size: JUN & 22,380 & $4,319-702,427$ \\
$q_{3}$ & Population size: PET & 80,966 & $20,750-565,946$ \\
$q_{4}$ & Population size: STA & 209,734 & $73,012-741,743$ \\
$q_{5}$ & Population size: KHO & 92,821 & $31,458-268,365$ \\
$q_{6}$ & Population size: ERI & 242,740 & $106,389-628,344$ \\
$q_{7}$ & Ancestral population size: KOD \& COR & 9,714 & $0-779,262$ \\
$q_{8}$ & Ancestral population size: KOD, COR, \& JUN & 11,258 & $0-664,233$ \\
$q_{9}$ & Ancestral population size: KOD, COR, JUN, \& PET & 46,603 & $1,503-334,038$ \\
$q_{10}$ & Ancestral population size: STA \& KHO & 211,003 \\
$q_{11}$ & Ancestral population size: KOD, COR, JUN, PET, STA, \& KHO & $49,613-115,848$ \\
$q_{12}$ & Ancestral population size: KOD, COR, JUN, PET, STA, KHO, \& ERI & 760,157 & $90,653-883,976$ \\
$t_{0}$ & Splitting time: KOD \& COR & 78,346 & $17,149-233,693$ \\
$t_{1}$ & Splitting time: NEP (KOD, COR, \& JUN) & 7,970 & $0-36,661$ \\
$t_{2}$ & Splitting time: NEP (KOD, COR, \& JUN) from NWP (PET) & 21,359 & $4,144-67,266$ \\
$t_{3}$ & Splitting time: STA from KHO & 46,863 & $19,447-107,434$ \\
$t_{4}$ & Splitting time: STA \& KHO from PET, KOD, COR, \& JUN & 102,971 & $45,588-189,683$ \\
$t_{5}$ & Splitting time: ERI from STA, KHO, PET, KOD, COR, \& JUN & 166,092 & $87,669-269,382$ \\
& & 214,549 & $120,823-321,665$
\end{tabular}




\section{Table 4(on next page)}

Demographic parameter estimates from $A B C$ modeling.

Posterior modal estimates ( $95 \%$ credible interval) of parameter valuesfrom the most probable biogeographic history (Scenario 1 ) inferred using $A B C$ modeling with DIYABC. Single parameter estimates are in units of effective population size $\left(\mathrm{n}_{1-7}\right)$ or time $\left(t_{\mathrm{a}-\mathrm{f}}\right)$ in generations. 
Table 4 Demographic parameter estimates from ABC modeling. Posterior modal estimates (95\% credible interval) of parameter values from the most probable biogeographic history (Scenario 1) inferred using ABC modeling with DIYABC. Single parameter estimates are in units of effective population size $\left(n_{1-7}\right)$ or time $\left(t_{a-f}\right)$ in generations.

\begin{tabular}{lllll}
\hline Parameter & Description & Mode & 95\% CI \\
\hline$n_{1}$ & COR $N_{e}$ & 144,000 & $53,000-197,000$ \\
9 & $n_{2}$ & KOD $N_{e}$ & 19,900 & $5,450-177,000$ \\
\hline$n_{3}$ & JUN $N_{e}$ & 21,200 & $7,730-158,000$ \\
$n_{4}$ & PET $N_{e}$ & 99,800 & $33,700-420,000$ \\
2 & ERI $N_{e}$ & 321,000 & $128,000-458,000$ \\
$n_{5}$ & KHO $N_{e}$ & 88,800 & $34,600-377,000$ \\
$n_{6}$ & STA $N_{e}$ & 315,000 & $122,000-485,000$ \\
$n_{7}$ & Splitting time: KOD from COR & 2,810 & $687-44,500$ \\
$t_{a}$ & Splitting time: COR from JUN & 22,400 & $7,730-120,000$ \\
$t_{b}$ & Splitting time: JUN from PET & 54,400 & $26,400-223,000$ \\
$t_{c}$ & Splitting time: STA from ERI & 205,000 & $98,100-363,000$ \\
$t_{d}$ & Splitting time: PET from ERI & 244,000 & $111,000-441,000$ \\
$t_{e}$ & Splitting time: KHO from ERI & 483,000 & $258,000-592,000$ \\
\hline$t_{f}$ & &
\end{tabular}


Figure 1

Four biogeographic scenarios evaluated with $A B C$ modeling.

Scenarios 1-3 (panels A-C, respectively) were based on the top (best-fitting) 100 trees from the IMa3 phylogeny selection step, each which contains a monophyletic grouping of northeastern Pacific populations with the Kamchatka population (PET). Scenario 4 (panel D) represents the null hypothesis that NEP populations share no close relationship to any northwestern Pacific population.
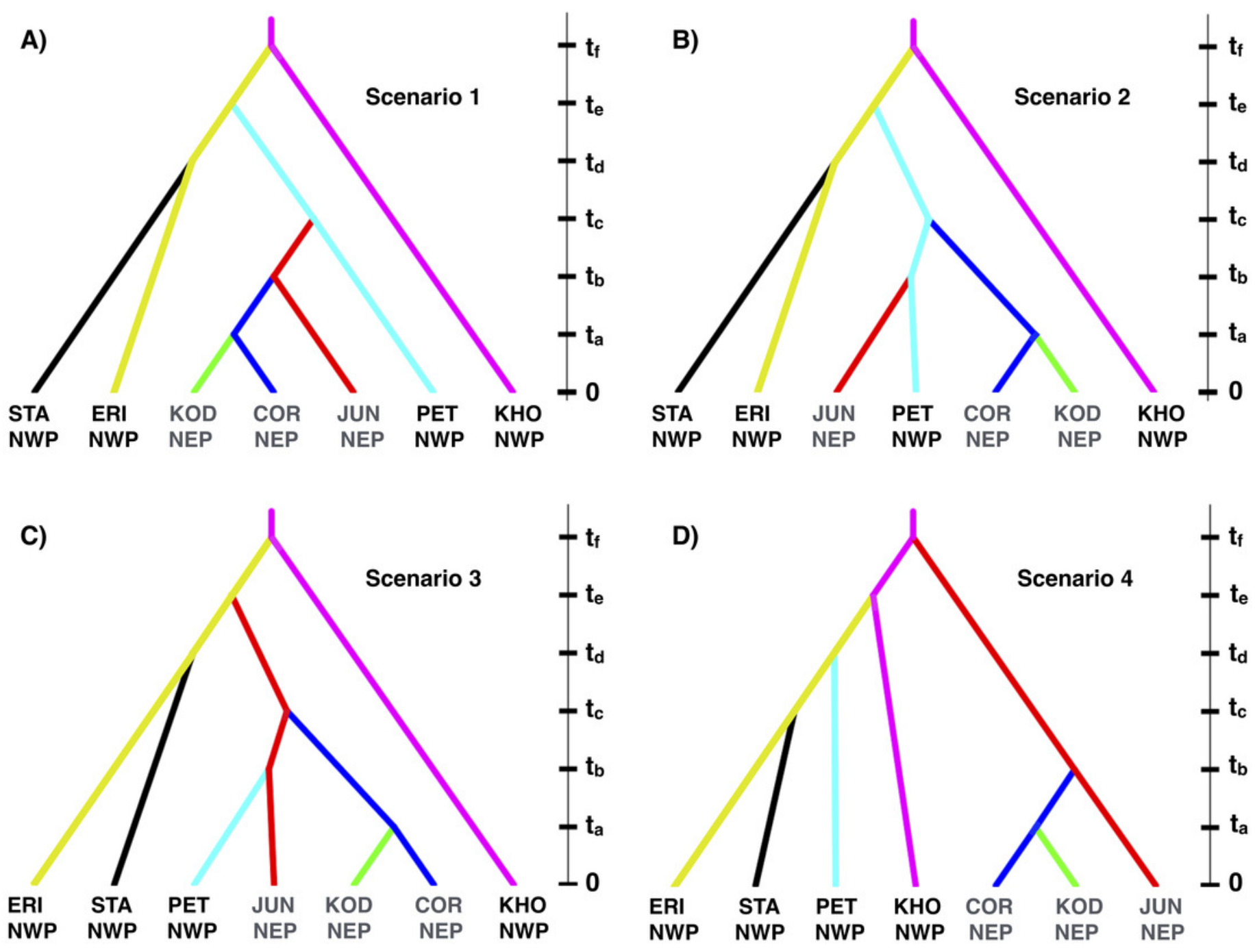


\section{Figure 2}

Unrooted minimum spanning mitochondrial CYTB haplotype network and haplotype frequencies

Each slash across a branch represents a single mutation. The size of each circle in each network is proportional to the sequence sample size $(\mathrm{N})$, with the smallest circle representing one haplotype copy. Blue haplotypes are restricted to the NWP, black restricted to the NEP, and green shared between the two regions.

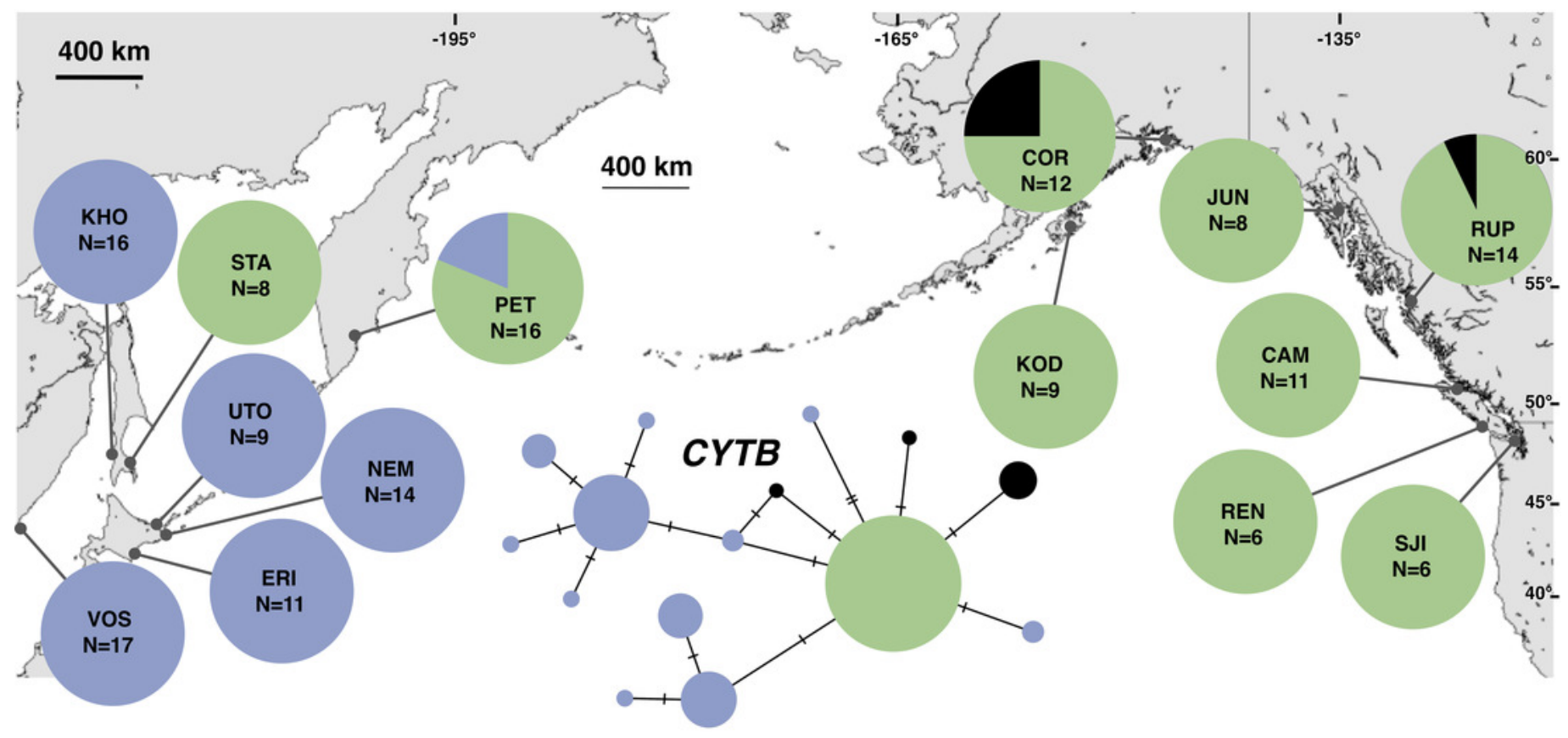




\section{Figure 3}

Unrooted minimum spanning nuclear ATPSa haplotype network and haplotype frequencies.

Each slash across a branch represents a single mutation. The size of each circle in each network is proportional to the sequence sample size $(\mathrm{N})$, with the smallest circle representing one haplotype copy. Blue haplotypes are restricted to the NWP, black restricted to the NEP, and green shared between the two regions.

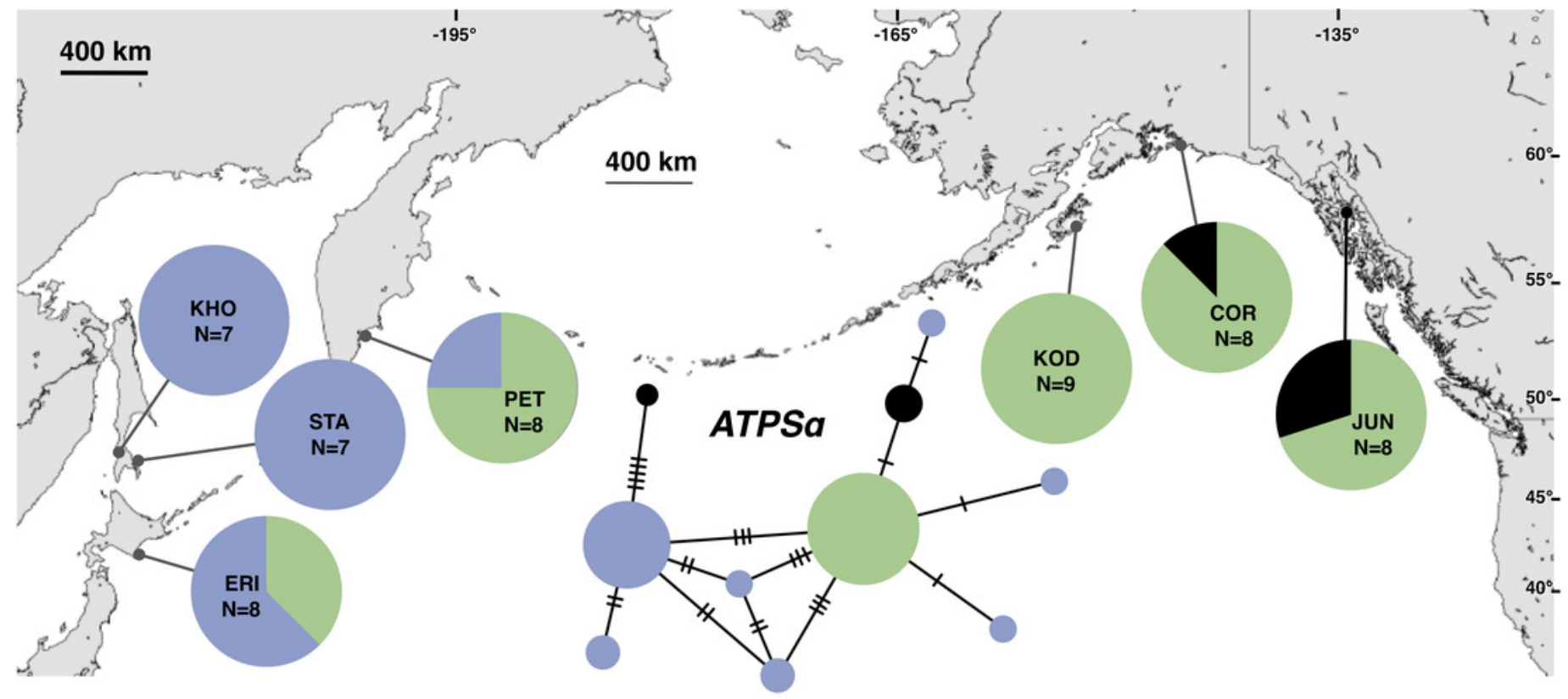




\section{Figure 4}

Unrooted minimum spanning nuclear ATPSb haplotype network and haplotype frequencies.

Each slash across a branch represents a single mutation. The size of each circle in each network is proportional to the sequence sample size $(\mathrm{N})$, with the smallest circle representing one haplotype copy. Blue haplotypes are restricted to the NWP, black restricted to the NEP, and green shared between the two regions.

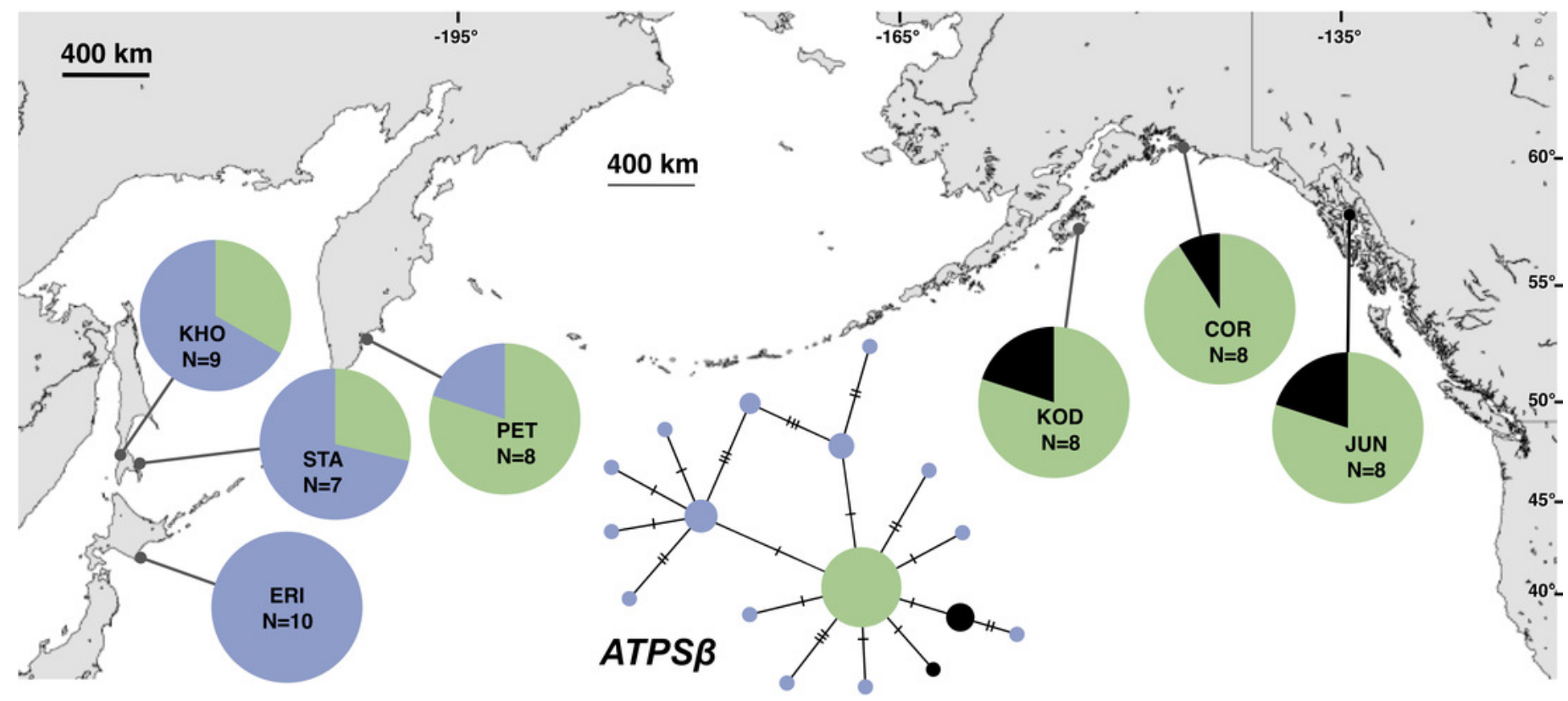




\section{Figure 5}

Unrooted minimum spanning nuclear APN54 haplotype network and haplotype frequencies.

Each slash across a branch represents a single mutation. The size of each circle in each network is proportional to the sequence sample size $(\mathrm{N})$, with the smallest circle representing one haplotype copy. Blue haplotypes are restricted to the NWP, black restricted to the NEP, and green shared between the two regions.

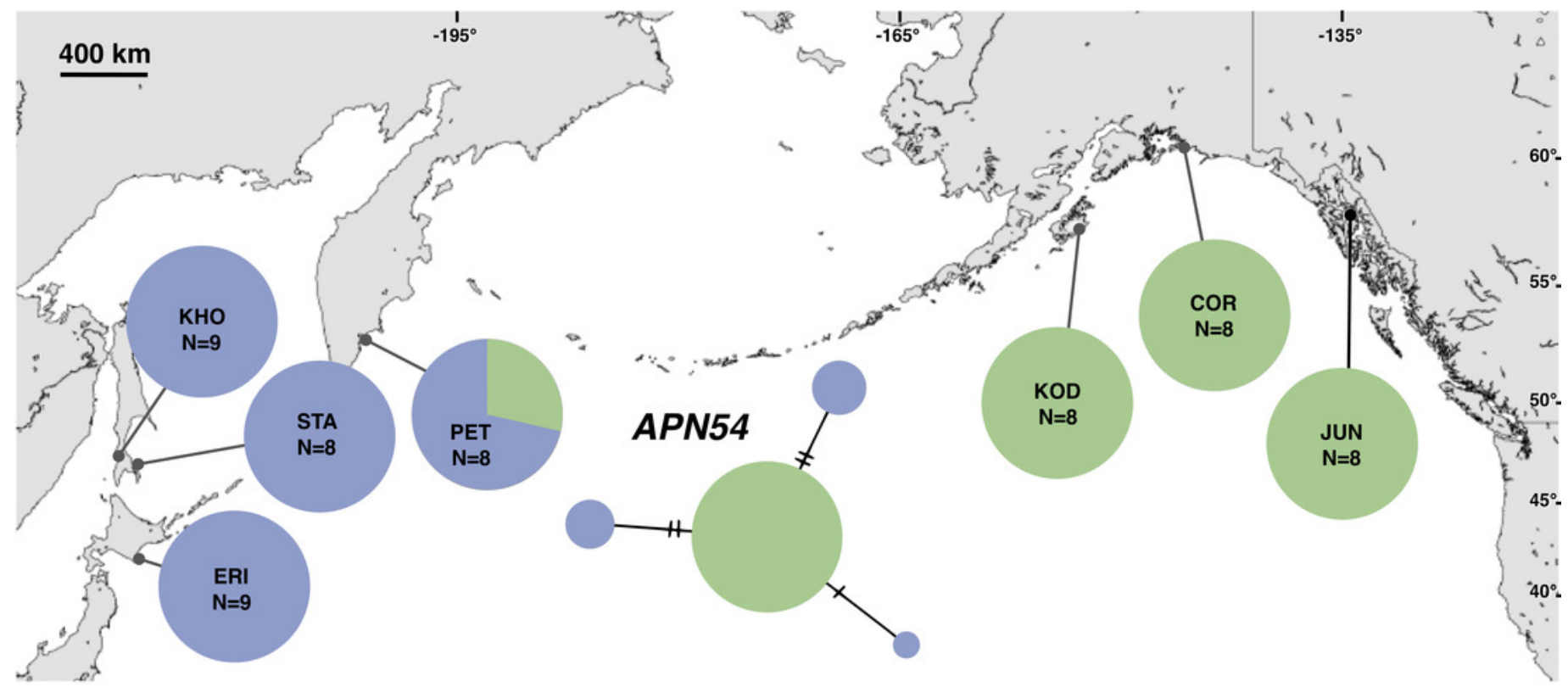


Figure 6

Multilocus posterior probability distributions for pairwise population divergence times.

Each curve is from a single pairwise comparison among samples in the northeastern Pacific (NEP) and northwestern Pacific (NWP).

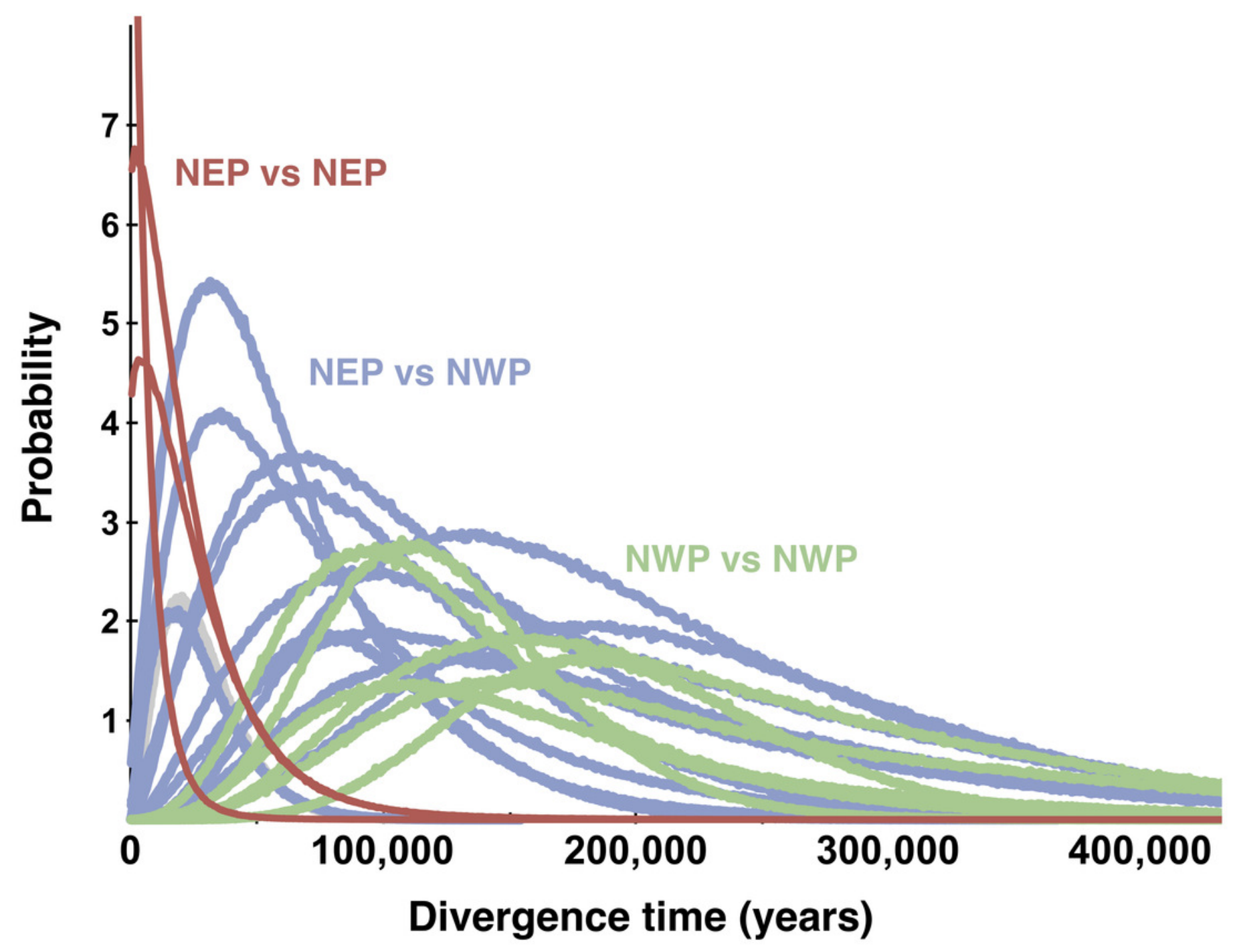


Figure 7

Posterior probabilities for four biogeographic scenarios evaluated with $A B C$ modeling.

The most likely scenario (Scenario 1) was identified with a polychotomous logistic regression computed with 50,000 simulated datasets with summary statistics that were most like those generated from the observed data

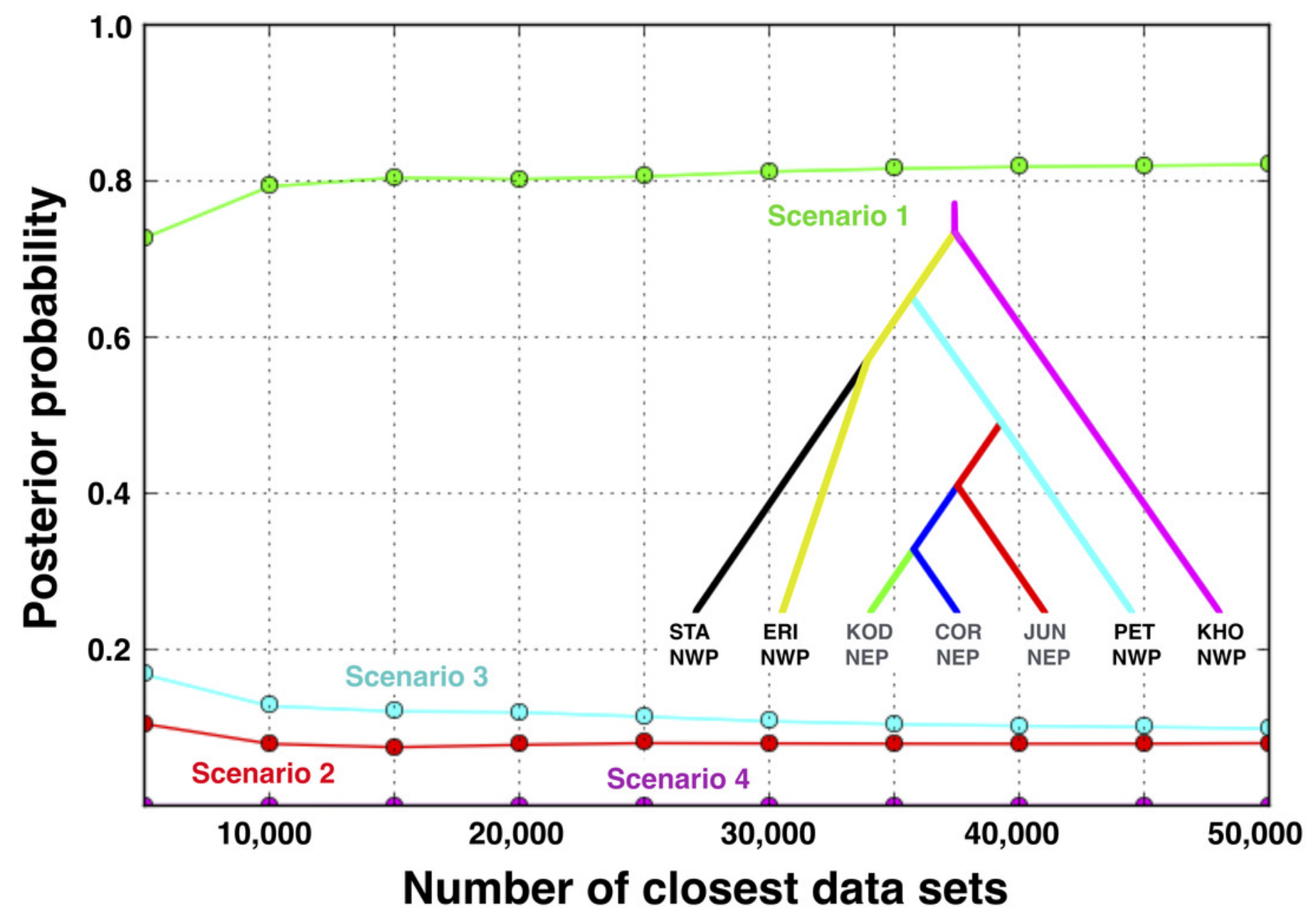




\section{Figure 8}

Multilocus demographic parameter estimates from IMa3.

(A) Best-fitting tree topology. Labels on branches and nodes correspond to effective population sizes (q0-12) and divergence times (to-5) in Table 3. (B) Posterior probability distributions for divergence times between northeastern Pacific (NEP) and northwestern Pacific (NWP) populations and corresponding temperature relative to present (data from Petit et al. 1999). (C) Posterior probability distributions for ancestral population sizes (q8-9). 


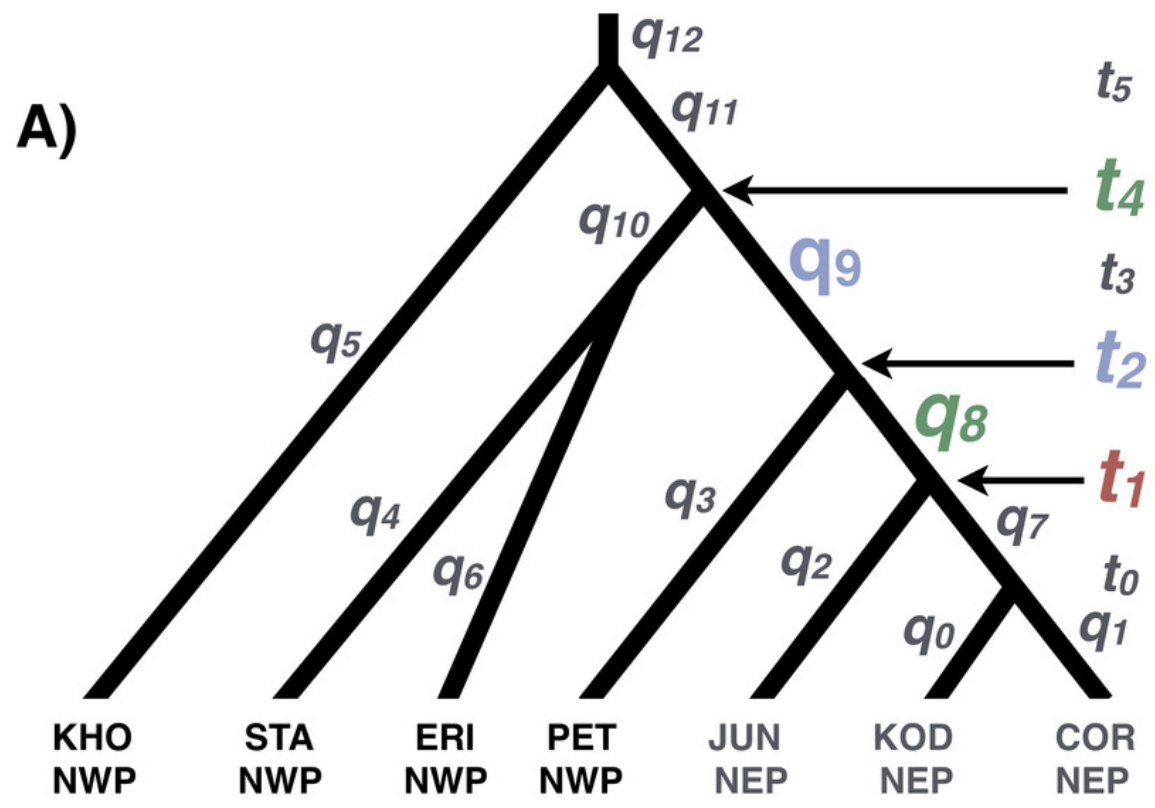

B)
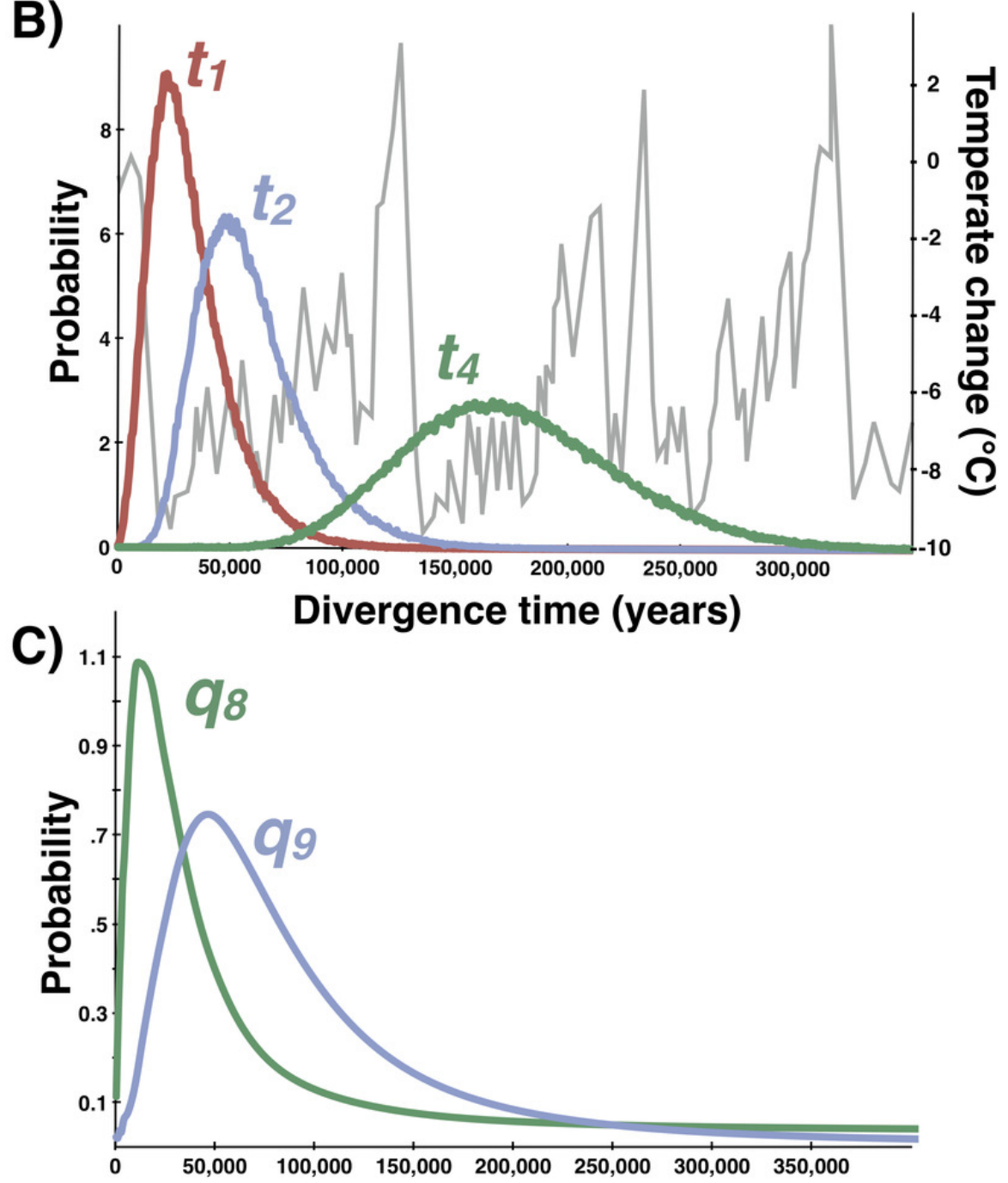

Effective population size (individuals) 